\title{
Capsule Commentary on Romanelli et al., Predictors of Statin Compliance after Switching from Branded to Generic Agents Among Managed-Care Beneficiaries
}

\author{
Himanshu Pathak, MD \\ Department of Cardiology, Prairie Heart Institute, Springfield, IL, USA.
}

J Gen Intern Med 29(10):1391

DOI: $10.1007 / \mathrm{s} 11606-014-2974-y$

(c) Society of General Internal Medicine 2014

$\mathrm{T}$ his interesting study by Romanelli et al. sought to identify demographic and clinical predictors of compliance after switching from branded to generic agents in an ambulatorycare setting. The investigators find that a majority of patients were compliant in the six months after switching. ${ }^{1}$ Higher compliance was associated with equivalent potency to the prior branded statin and higher pre-switch compliance. ${ }^{1}$ Lower compliance was seen among Hispanic patients. The authors concluded that there is a potential for non-compliance to generic statin therapy, particularly among Hispanic patients or when dose/potency is increased. ${ }^{1}$

All generic drugs approved by U.S. Food and Drug Administration (FDA) have the same high quality, strength, purity and stability as brand-name drugs. ${ }^{2}$ The generic manufacturing, packaging, and testing sites must pass the same quality standards as those of brand name drugs. ${ }^{2}$ The idea of switching to generics has direct impact on healthcare costs and is therefore an important one.

Latino Americans are significantly more likely than their majority counterparts to receive care in hospital out-patient departments and emergency rooms, and might have to depend on house-staff as primary providers. ${ }^{3,4}$ They are less likely to have a primary care physician and continuity of care. ${ }^{3,4}$ The known factors for non-compliance include: poor continuity of care, limited English proficiency, lack of family or social support, unstable living conditions, lack of health insurance and medication cost. Whether these factors have a role in this set of Hispanic patients has not been evaluated in this study. These factors related to non-compliance might have been present in this set of the Hispanic population, and might have been the reason for poor compliance in this group of patients.

The authors have done a commendable job by highlighting some predictors of non-compliance, the most significant being baseline pre-switch compliance. The right next step would be the development of interventions to improve baseline compliance through better patient education, removal of language barriers, continuity of care and closer follow-up during initiation, dose/potency increases and switch to a generic drug.

Conflict of Interest: The author has no conflict with any of the material in this manuscript.

Corresponding Author: Himanshu Pathak, MD; Department of CardiologyPrairie Heart Institute, Springfield, IL, USA (e-mail: hpathak@prairieheart.com).

\section{REFERENCES}

1. Romanelli RJ, Segal JB. Predictors of Statin Compliance after Switching from Branded to Generic Agents among Managed-Care Beneficiaries. J Gen Intern Med: (DOI: 10.1007/s11606-014-2933-7)

2. www.fda.gov/Drugs / Resources ForYou / Consumers / BuyingUsingMedicineSafely/UnderstandingGenericDrugs/default.htm

3. Lillie-Blanton M, Martinez RM, Salganicoff A. Site of medical care. Do racial and ethnic differences persist? Yale J Health Policy, Law, Ethics. 2001;1:1-17.

4. Guinn K. Working Without Benefits: The Health Insurance Crisis Confronting Hispanic-Americans. New York: The Commonwealth Fund; 2000 .

Published online August 8, 2014 